\title{
Childhood obesity and the income gradient: Evidence from Australia
}

\author{
Son Nghiem ${ }^{a *}$ and Rasheda Khanam ${ }^{b}$ \\ ${ }^{a}$ Australian Centre for Health Services Innovation \\ Queensland University of Technology, Kelvin Groves, Australia \\ ${ }^{b}$ School of Commerce \\ University of Southern Queensland, Toowoomba, Australia
}

\begin{abstract}
This paper examines the dynamic nature of human capital formation in the context of childhood obesity and the association of household income and childhood obesity in Australia using the first five waves of the Longitudinal Study of Australian Children (LSAC). Our results show a strong evidence of dynamic nature of child obesity: the lag obesity is a significant and robust predictor of obesity in the current period. We also found that the main channel for childhood obesity is inter-generational trait: the probability of obesity in children born to an obese mother or father is $15 \%$ higher than that of other children. Other important determinants are lifestyle factors, including the consumption of drinks with a high sugar content and the amount of time watching TV. Income becomes an insignificant determinant of childhood obesity once we control for unobserved individual heterogeneity.
\end{abstract}

Keywords: Childhood obesity, income gradient, Australia

JEL Codes: I10; I12

${ }^{*}$ Corresponding author, son.nghiem@qut.edu.au 


\section{Introduction}

The incidence of childhood obesity is increasing at an alarming rate across the world (Wang and Lobstein, 2006). Australia is no exception: the National Health Survey 2008 showed that the incidence of obesity among children aged 7-15 was 25 per cent (Australian Bureau of Statistics, 2009), which is about double the rate of the 1980s. Childhood obesity is associated with adverse health consequences and risk factors including psychological stress, Type 2 diabetes and metabolic syndrome (Freedman et al., 2007; Whitlock et al., 2005; Han et al., 2010; Sutherland, 2008; Dietz, 1998; Janicke et al., 2008). Obese children and adolescents are at higher risk of experiencing social and psychological problems-such as discrimination and poor self-esteem-which can continue into adulthood (Williams et al., 2005; Dietz, 1998; Cawley, 2008). Childhood obesity is also estimated to impose a heavy economic burden on society, and has been estimated to be responsible for 2.0-3.5 per cent of medical expenditure (Thompson and Wolf, 2001). Many studies confirm that the costs of medical services among obese children are significantly higher than those of children within a healthy weight range (Wenig et al., 2011; Kuhle et al., 2011; Au, 2012). In Australia, the estimated direct and indirect costs of obesity and obesity-related illnesses was $\$ 37.7$ billion in 2008/09, whereas the costs related to productivity loss due to absenteeism and premature death was estimated to be $\$ 6.4$ billion per year (Medicare Australia, 2010).

The literature indicates that household income is an important determinant of childhood obesity. In particular, the prevalence of obesity is higher among low-income households in developed countries (Baltrus et al., 2007; Bhargava et al., 2008; Baum II and Ruhm, 2009; Stamatakis et al., 2010; Murray et al., 2011; El-Sayed et al., 2012; Chia, 2013; Walsh and Cullinan, 2015) but the trend is reversed in developing countries (Nguyen et al., 2007; Mushtaq et al., 2011; Zere et al., 2012). To the best of our knowledge, no study to date has examined the effects of income on childhood obesity using a dynamic specification. The contribution of this paper is the application of dynamic nature of human capital model by Heckman (2007), and Cunha and Heckman (2007) in the context of child obesity. We use child's previous obesity status as an independent variable to investigate the dynamic nature of obesity. Cunha and Heckman (2007) and Heckman (2007) examined this issue in children's skill formation and found that child's current cognitive and non-cognitive outcomes are shaped by previous cognitive and non-cognitive outcomes. Further, only 
few studies have examined the relationship between obesity status of children and income over time. In this study, we address these gaps in the literature using the household level data from the Longitudinal Study of Australia Children (LSAC). We develop an innovative approach that combines the richness of the LSAC data set with a Hausman specification test to mitigate effects of unobserved individual characteristics. We apply an extended random effects model by Wooldridge (2005) to empirically investigate the determinants of child obesity. We also test for the hypothesis that the effects of household income on childhood obesity follow the law of diminishing marginal return.

Our results reveal a strong dynamic relationship. A child's current level of obesity is highly correlated with his/her previous obesity status. We also find that that when only a basic sets of covariates are used, childhood obesity is likely to be common among children from low SES households. However, the relationship between income and childhood obesity becomes insignificant if we consider dynamic nature of human health capital development and unobserved heterogeneity. Our results support the hypothesis that childhood obesity is correlated with parental obesity, consumption of drinks with high sugar content and watching TV.

\section{Methodology}

Based on the theory of dynamic nature of human capital formation (Grossman, 1972; Cunha and Heckman, 2007; Heckman, 2007), we argue that obesity status in the current period will also be strongly associated with obesity status in the previous period. Other possible determinants of childhood obesity include genetics, energy intake (amount and frequency of food and drinks consumption), energy spend (frequency and level of physical activities), and the efficiency of the energy conversion process (metabolism). The living environment (e.g., neighbourhood characteristics), that is static, also affects the intake and metabolization of energy and hence child obesity. Household income can affect the obesity status of children via observable factors such as the provision of food/drinks and enrolments in sport activities. Thus, the balance of energy is potentially affected by both observable factors such as calorie intake (e.g., consumption of food and drinks), calorie spending (e.g., physical activities), characteristics of the individuals, households, and external environment; and unobservable factors such as genetic inheritance ("nature") and latent (possibly, learned) attitudes towards eating, exercises and so on. Unobservable factors such as genetic inheritance may 
affect both the incidence of obesity and the regressors of interest such as household income; hence analyses on determinants of obesity may produce biased results if one ignores this issue.

Taking into account the dynamic nature of the human health capital model, and the presence of unobservable factors such as genetics and personality traits, the analysis of obesity determinants can be specified as below

$$
y_{i t}^{*}=\gamma y_{i, t-1}^{*}+\alpha I_{i t}+\beta X_{i t}+u_{i}+\varepsilon_{i t}(i=1,2, \ldots, N ; t=1,2, \ldots T)
$$

where $y_{i t}^{*}$ is the latent variable of child obesity that is observed by the child's obesity status $\left(y_{i t}\right)$, coded as one if $y_{i t}^{*}>0$ and zero otherwise. The variable $I_{i t}$ represents household income; $X_{i t}$ is a set of variables representing individual characteristics, household characteristics and environmental factors; $u_{i}$ is the set of time-invariant unobserved individual effects (e.g., genetic, persistence, discipline); and $\varepsilon_{i t}$ is the random noise.

Under the assumption that the conditional probability $y_{i t}=1$ follows standard cumulative normal distribution, we can estimate Equation (1) using a probit estimator. If the conditional probability that $y_{i t}=1$ is assumed to follow a cumulative logistic distribution, Equation (1) can be estimated using a logit estimator. The main challenge is that the presence of a set of unobserved individual effects $\left(u_{i}\right)$, potentially violates the basic assumption in regression analysis that the error term be uncorrelated with the regressors, and hence the results could be biased.

Four strategies can be used to control for individual unobserved characteristics. First, individual unobserved characteristics can be controlled for using data that include information about identical twins (Webbink et al., 2010; Price and Swigert, 2012). Since identical twins share the same genetic inheritance from their parents and growing environments, any differences in their obesity status must be accounted for by other factors. Second, the IV approach seeks to identify variables that correlate with the endogenous variables (e.g., household income) but are uncorrelated with the child's obesity status. Anderson et al. (2003) argued that unemployment rate, child care regulations, wages of child care workers, welfare benefit level and states of welfare reforms could be selected as IVs in analysing the effects of maternal employment on child obesity. However, one may argue that these factors may affect child obesity incidence via mother's income 
and mental health status. Thus, finding good IVs is practically difficult and we were unable to find a good IV candidate in this study. Third, one can mitigate effects of unobserved individual effects by controlling for a large set of exogenous variables. The implicit assumption of this approach is that effects of unobservable factors are proportionally related to effects of observable factors. Thus, when the number of observable variables controlled for is large enough, effects of unobservable characteristics are mitigated. Fourth, one can control for unobserved individual characteristics using panel data methods, namely fixed-effects (FE) and random-effects (RE) estimators. In the case of binary dependent variables as in this study, one can apply the conditional fixed effects estimator by Chaimberlain (1980), where the likelihood function does not depend on time-invariant individual characteristics $\left(u_{i}\right)$. However, this property of the likelihood function only works for logit regressions and it cannot estimate marginal effects. In addition, the estimator discards observations that the dependent variable did not change its states (e.g., from obesity to non-obesity) over waves; resulting in a considerable loss of observations in studies like ours. The traditional RE estimator assumes that unobserved individual characteristics are normally distributed and independent of exogenous regressors. The estimation of a dynamic specification like Equation (1) faces an "initial condition problem" that the first observation of dependent variable $\left(y_{i, 0}\right)$ is correlated with $u_{i}$. Wooldridge (2005) proposed a simple solution that express the unobserved individual characteristics as a function of initial observation and other observable regressors

$$
u_{i}=\delta_{0}+\delta_{1} y_{i, 0}+\delta_{2} Z_{i t}+r_{i t}
$$

where $y_{i, 0}$ is the first observation of $y_{i}, Z_{i t}$ are exogenous variables, which may include $X_{i t}$, and $r_{i t}$ is random errors. Thus, Equation (1) can be estimated using a standard RE approach after replacing $u_{i}$ with that in Equation (2). In this study, we define $y_{i, 0}$ as the obesity status of children in Wave 1. One method to choose between the FE and RE estimators is to utilise the Hausman test, which compares the common parameters of the two estimates. If the null hypothesis that the two estimators produce the same parameters is rejected, the FE estimator is preferred because it produces consistent estimates in the presence of unobserved heterogeneity. If the test fails to reject the null hypothesis, the RE estimator is preferred because it is more efficient (i.e., produce lower standard errors).

In this study, we develop an innovative approach that combines the richness of the LSAC data set with 
a Hausman specification test to mitigate effects of unobserved individual characteristics. We commence by estimating Equation (1) using a basic set of covariates and then continue to add more covariates until the Hausman test does not reject the null hypothesis. Our rationale is that, when only a basic set of covariates is controlled for, the FE estimator will be preferred because the RE estimator still leave ample room for unobserved individual effects. The ability of RE estimator to mitigate unobserved individual effects increases as more observable covariates are controlled for. This argument is similar to the model specified by Altonji et al. (2005), who argued that selection on unobservables are proportional to selection on observables, hence the more observable covariates are controlled for, the effects of unobservables are minimized. Thus, we argue that when the Hausman specification test prefers the RE estimator, its ability to address unobserved individual effects are similar to that of the FE estimator.

\section{Data}

\subsection{Data sources}

In this study, we use the first five waves of the Longitudinal Study of Australian Children (LSAC), which is a nationally representative survey first conducted in 2004 and then repeated every two years until 2018 (Soloff et al., 2005). The survey includes two cohorts: children born between March 2003 and February 2004 (B-Cohort), and between March 1999 and February 2000 (K-Cohort). The data were collected using a two-stage clustered sampling survey, where postcodes were used as the primary sampling unit. The LSAC sample contains approximately 5000 children in each cohort, with an average of 20 children per cohort, per postcode. The final respondent samples for the B Cohort consist of 5107, 4606, 4386, 4242 and 4085 children in Waves 1,2,3,4 and 5, respectively.The sample size for the K Cohort is 4982, 4464, 4331, 4169 and 3956 children for Waves 1, 2, 3, 4 and 5 respectively.

\subsection{Measurement of key variables}

In line with the literature (e.g., Anderson et al., 2003), we define children as obese when their BMI is greater than the $95^{\text {th }}$ percentile of the BMI population distribution based on the growth chart published by 
the Center for Disease Control and Prevention (Kucamarski et al., 2002). The data on weight and height that used in calculation of children BMI were measured by LSAC surveyors. In this study, we calculate the household income as the sum of weekly income of mother and father then multiply by 52 to calculate annual income. We convert nominal income to real income using consumer price index (Australian Bureau of Statistics, 2015), selecting the price level of the first wave (2004) arbitrarily as the base period. To reflect better the living standard of households, we also convert household income to adult-equivalent income by dividing household income to the square root of household size, which is one popular option to convert income into adult-equivalent scale (Solt, 2009). Finally, we standardise the distribution of adult-equivalent income for the ease of interpretation. For example, because one standard deviation above or below mean income is used in the literature to classify socio-economic status (Kennedy et al., 1998), the standardisation of income makes us able to interpret movement of income parameters by one unit as effects of changing socio-economic status.

The summary statistics reported in Table 1 show that there are significant differences in most characteristics of obese and non-obese children. Some exceptions include household size, consumption of high fat food, the proportion of families with most out-of-home activities, and neighbourhood facilities. In particular, boys are more likely to be obese than girls and obese children are less likely to live in households that speak English at home.

The obesity incidence is $4.8 \%$ among children with Aboriginal and Torres Strait Islander (ATSI) background and 3.1\% among non-ATSI children. Obese children live in lower income households $(\$ 70,000$ per year on average) despite their parents working longer hours (27 hours per week for mother and 47 hours per week for fathers, on average), compared with those of non-obese children (average annual household income is $\$ 83,000$, and average working hours per week are 25.7 for mothers and 46.5 for fathers). This observation suggests that parents of obese children are more likely to work in low paid jobs.

Parents of obese children have less education (57\% of mothers and $48 \%$ of fathers completed Year 12) than parents of non-obese children (66\% of mothers and 58\% of fathers completed Year 12). The parents of obese children also exercise less but difference is not substantial. The mothers and fathers of obese children exercise 2.8 hours and 3.1 hours per week, respectively, while the mothers and fathers of non-obese children exercise 2.9 and 3.2 hours per week, respectively. Parents of obese children are also less likely to 
stay together, slightly younger, have poorer physical and mental health, and more likely to be obese. Obese children spend more time watching TV and consume more drinks with high sugar content but there is no significant difference in the consumption of high-fat food. Finally, the families of obese children appear to live in neighbourhoods with poorer socio-economic status (proxied by percentage of people who have Year 12 education and speak English). Nevertheless, there was no difference in access to basic facilities (e.g., parks, library and public transport).

- Insert Table 1 about here -

The concentration curves in Figure 1 confirm that the incidence of child obesity is higher among poorer households. Note that all concentration curves lie above the $45^{\circ}$ line, or line of perfect equality, suggesting that the incidence of child obesity is higher among poor households and that inequality has increased over time. The visual observation is confirmed by concentration indices $(\mathrm{CI})^{1}$, which increase sharply (in absolute value) from -0.06 in Wave 1, -0.1 in Wave 2, -0.102 in Wave 3, -0.14 in Wave 4 to -0.16 in Wave 5. Therefore, the income gradient of child obesity may increase as the child ages (i.e., over survey waves); however, this hypothesis does not consider other covariates.

-Insert Figure 1 about here -

\section{Results}

We utilise the richness of LSAC data to address individual heterogeneity by controlling for a comprehensive set of covariates as suggested by Gregg et al. (2005) (i.e., a detailed picture of observable heterogeneity). Murnane and Willett (2010) have argued that relying solely on a rich set of covariates to address the issue of endogeneity does have some limitations. We therefore incorporate the Hausman specification test to develop an optimal model, which mitigates heterogeneity while maintaining a relatively parsimonious specification. The results ${ }^{2}$ show that, only when a very basic set of covariates (i.e., parents' obesity status, age, gender of

\footnotetext{
${ }^{1} \mathrm{CI}$ is defined as twice the area between the concentration curves and the $45^{0}$ line and ranges from -1 to 1 . A CI of zero (i.e., concentration curve coincides with the $45^{0}$ line) reflects perfect equality; a negative CI suggests obesity is greater among the poor and a positive CI suggests the rich has higher rate of obesity.

${ }^{2}$ Since tparameters of probit/logit estimators with different covariates are not comparable (Norton, 2012), we do not report the results of this basic specification (but they can be made available from the authors upon request). We focus instead on the significance of income parameters to show that this simple specification can over estimate the effects of income. We thank an anonymous reviewer for reminding us of this issue.
} 
children, the ATSI status, and English spoken at home) and a RE estimator are used, family income becomes a significant determinant of child obesity. ${ }^{3}$ However, the quadratic term of income is not significant despite having the expected positive sign. In addition, in this basic model, the FE estimator is preferred according to the Hausman specification test.

To exploit the richness of LSAC data, we select control variables in the following groups: energy inputs and outputs (consumption of food, drinks, leisure and physical activities), family traits (obesity status of parents), culture (ATSI status and English spoken at home), family environment (out-of-home activities, the level of exercise of parents), and living environment (neighbourhood characteristics) as identified in previous studies. Selection of potential variables for each group is based on the number of observations and correlations among possible pairs (i.e., selecting one variable with most number of observations among highly correlated pairs of similar variables within a group). We find that when two variables in each group are selected, the Hausman specification test failed to reject the null hypothesis that common parameters of the RE and FE estimators are similar (test statistics $=4.34$, $\mathrm{p}$-value $=0.22$ ). Thus, when a comprehensive covariate with at least two variables from each group are selected, effects of unobserved individual characteristics are mitigated, and hence, the RE estimator is preferred.

Table 2 shows that the household income per adult equivalent and its quadratic are not significant when a comprehensive set of covariates are included. We report the RE probit estimator instead of logit estimator for the ease of interpretation (i.e., probability of being obese). The lag of obesity and the obesity status in the first wave are a significant determinant of obesity status in the current period. In particular, obese children in the previous period have a $20.6 \%$ higher probability of being obese.

\footnotetext{
${ }^{3}$ We do not present the result of this naive model for brevity and since comparison paramters of probit/logit estimators with different controls are not advisable (Norton, 2012). But this result can be obtained from the authors upon request.
} 
Table 1: Household income and obesity status: Random Effects Probit Estimator

\begin{tabular}{|c|c|c|c|}
\hline Variables & Coefficients & Standard errors & Marginal effects \\
\hline Lag obese & $* * * 1.681$ & 0.182 & 0.206 \\
\hline Obese in Wave 1 & $* * * 1.047$ & 0.325 & 0.075 \\
\hline Income per adult-equivalent & 0.081 & 0.224 & 0.002 \\
\hline Income squared & -0.006 & 0.028 & -0.0002 \\
\hline Mother is obese $(\mathrm{Y}=1)$ & $* * * 0.403$ & 0.136 & 0.015 \\
\hline Father is obsed $(\mathrm{Y}=1)$ & $* * * 0.386$ & 0.127 & 0.014 \\
\hline English spoken at home $(\mathrm{Y}=1)$ & $* *-0.491$ & 0.203 & -0.022 \\
\hline ATSI status $(\mathrm{Y}=1)$ & 0.181 & 0.343 & 0.006 \\
\hline Gender of the child (Y=1) & -0.064 & 0.110 & -0.002 \\
\hline Both parents at home $(Y=1)$ & -0.287 & 0.249 & -0.011 \\
\hline Child's age (months) & 0.023 & 0.019 & 0.001 \\
\hline Serves of high fat food & -0.029 & 0.054 & -0.001 \\
\hline Serves of high sugar drinks & $* * 0.115$ & 0.049 & 0.003 \\
\hline Hours watching TV/days & $* 0.127$ & 0.077 & 0.003 \\
\hline Out of home activities index & 0.010 & 0.047 & 0.0003 \\
\hline Mother completed Year $12(\mathrm{Y}=1)$ & -0.133 & 0.126 & -0.004 \\
\hline Father completed Year $12(\mathrm{Y}=1)$ & -0.113 & 0.124 & -0.003 \\
\hline Mother has good health $(\mathrm{Y}=1)$ & -0.024 & 0.126 & -0.001 \\
\hline Father has good health $(\mathrm{Y}=1)$ & 0.064 & 0.118 & 0.002 \\
\hline Mother's depression scale & $* * 0.253$ & 0.126 & 0.007 \\
\hline Father's depression scale & 0.156 & 0.113 & 0.004 \\
\hline Mother's days of exercise per week & -0.046 & 0.032 & -0.001 \\
\hline Father's days of exercise per week & 0.017 & 0.026 & 0.0005 \\
\hline Mother's average hours worked per week & 0.005 & 0.004 & 0.0001 \\
\hline Father's average hours worked per week & $* * * 0.012$ & 0.004 & 0.0003 \\
\hline$\%$ completed Year 12 in neighbourhood & $*_{-0.010}$ & 0.006 & -0.0003 \\
\hline$\%$ speak English in neighbourhood & -0.008 & 0.005 & -0.0002 \\
\hline Neighbourhood facilities & -0.054 & 0.082 & -0.001 \\
\hline Time trend (wave) & 0.783 & 1.124 & 0.021 \\
\hline Wave $\times$ income per adult-equivalent & -0.090 & 0.099 & -0.002 \\
\hline Constant & $* * *-5.280$ & 1.262 & \\
\hline$\sigma_{u}$ & $* * * 0.671$ & 0.210 & \\
\hline Number of observations & 3267 & & \\
\hline $\mathrm{BIC}$ & 1237 & & \\
\hline AIC & 1042 & & \\
\hline Log-Likelihood & -489 & & \\
\hline
\end{tabular}

Other important determinants of childhood obesity include the obesity status of mother and father: children of an obese mother or father have a $1.5 \%$ higher probability of being obese. Children from households who speak English at home have 2.2\% lower probability of being obese. Among the energy inputs outputs 
channels, the consumption of drinks with a high sugar content is significantly associated with obesity. Serving one more high sugar drink per day or one additional hours of watching TV per day is associated with an increase to the probability of child obesity by $0.3 \%$. Physical and mental health status of parents appears to play an important role in determining the obesity status of children. In particular, children of depressed mothers are significantly associated with higher probability of being obese. The marginal effects of mother's depression scale to obesity of the child are $0.7 \%$ but effects of the obesity status of father are not significant. Likewise, children of fathers who spend longer working hours are also significantly more likely to be obese. One additional hours of work per week by fathers is associated with a $0.03 \%$ increase in the probability of their children being obese. Neighbourhood characteristics also have strong effects on childhood obesity. The probability of child obesity is significantly lower among households living in neighbourhood with high percentage of people completed Year 12. However, the significant level is only $10 \%$ and the marginal effects are modest: one percent increase in the number of people completed Year 12 in the neighbourhood is associated with $0.03 \%$ reduction in the probability of child obesity.

To test the sensitivity of analysis, we select alternative measures of obesity: 1) those who have weightfor-age (measured by surveyors) score at 95 percentile or higher; and 2) a self-reported measure of obesity that define as those selected last choice of an 4-point Likert scale question on their child weight ${ }^{4}$. The results reported in Table 3 are consistent with that in Table 2. One major different is that income remained a significant determinant of child obesity when weight-for-age is selected to determine children's obesity status. However, the significant level is only at 10 percent and the magnitude is modest: an increase of adult-equivalent income by one standard deviation is associated with only $2 \%$ reduction in the probability of child obesity. In addition, the positive and significant result of the quadratic term of income suggests that the marginal effects diminish as income increases. Lag obesity and the obesity status in Wave 1 are the most significant determinants of child obesity. The marginal effects of those who were obese in the last period are $25 \%$ and $18.7 \%$ for obesity defined by weight-for-age and self-reported, respectively. Likewise, children of obese father or mother are significantly more likely to be obese while the probability of childhood obesity is significantly lower in English-spoken households.

\footnotetext{
${ }^{4}$ These 4-point answers are: 1) Underweight, 2) Normal weight, 3) Somewhat overweight, and 4) Very overweight. We define self-reported obesity if children are in option 4.
} 
Table 2: Household income and obesity status: sensitivity tests

\begin{tabular}{|c|c|c|c|c|}
\hline \multirow[t]{2}{*}{ Variables } & \multicolumn{2}{|c|}{ Weight-for-age } & \multicolumn{2}{|c|}{ Self-reported } \\
\hline & Coefficients & Marginal effects & Coefficients & Marginal effects \\
\hline Lag obese & $* * * 1.364$ & 0.25 & $* * * 1.467$ & 0.187 \\
\hline Obese in Wave 1 & $* * * 1.081$ & 0.17 & $* * * 0.693$ & 0.044 \\
\hline Income per adult-equivalent & $*_{-0.260}$ & -0.02 & -0.120 & -0.004 \\
\hline Income squared & $* 0.028$ & 0.002 & 0.011 & 0.0003 \\
\hline Mother is obese $(\mathrm{Y}=1)$ & $* * * 0.490$ & 0.051 & $* * * 0.483$ & 0.023 \\
\hline Father is obsed $(\mathrm{Y}=1)$ & $* * * 0.401$ & 0.038 & $* * * 0.398$ & 0.017 \\
\hline English spoken at home $(\mathrm{Y}=1)$ & $* *-0.296$ & -0.028 & $* * *_{-}-0.443$ & -0.021 \\
\hline ATSI status $(Y=1)$ & 0.176 & 0.016 & 0.338 & 0.015 \\
\hline Gender of the child $(Y=1)$ & 0.076 & 0.006 & -0.123 & -0.004 \\
\hline Both parents at home $(Y=1)$ & -0.160 & -0.014 & $* * *_{-}-0.450$ & -0.023 \\
\hline Child's age (months) & $* * *-0.008$ & -0.001 & $* * * 0.008$ & 0.0003 \\
\hline Serves of high fat food & -0.016 & -0.001 & -0.022 & -0.001 \\
\hline Serves of high sugar drinks & 0.037 & 0.003 & $* * * 0.102$ & 0.003 \\
\hline Hours watching TV/days & 0.067 & 0.005 & 0.026 & 0.001 \\
\hline Out of home activities index & $*_{-} 0.057$ & -0.0043 & 0.031 & 0.001 \\
\hline Mother completed Year $12(\mathrm{Y}=1)$ & -0.005 & -0.0004 & -0.002 & -0.00005 \\
\hline Father completed Year $12(\mathrm{Y}=1)$ & $* *_{-} 0.007$ & -0.0006 & -0.004 & -0.0001 \\
\hline Mother has good health $(\mathrm{Y}=1)$ & 0.016 & 0.001 & 0.064 & 0.002 \\
\hline Father has good health $(\mathrm{Y}=1)$ & -0.005 & -0.0004 & -0.081 & -0.003 \\
\hline Mother's depression scale & 0.010 & 0.001 & 0.000 & 0.00001 \\
\hline Father's depression scale & -0.123 & -0.01 & -0.043 & -0.001 \\
\hline Mother's days of exercise per week & -0.008 & -0.001 & 0.049 & 0.002 \\
\hline Father's days of exercise per week & 0.088 & 0.007 & -0.015 & -0.0005 \\
\hline Mother's average hours worked per week & 0.005 & 0.0004 & -0.029 & -0.0009 \\
\hline Father's average hours worked per week & 0.026 & 0.002 & -0.012 & -0.0004 \\
\hline$\%$ completed Year 12 in neighbourhood & 0.012 & 0.0009 & 0.022 & 0.0007 \\
\hline$\%$ speak English in neighbourhood & -0.000 & -.000005 & $* * 0.007$ & 0.0002 \\
\hline Neighbourhood facilities & $* * * 0.008$ & 0.0006 & $* 0.005$ & 0.0002 \\
\hline Time trend (wave) & $*_{-1.201}$ & -0.091 & -0.555 & -0.017 \\
\hline Wave $\times$ income per adult-equivalent & $* 0.127$ & 0.01 & 0.060 & 0.002 \\
\hline Constant & $*_{-}-1.583$ & 1.262 & $* * *-2.473$ & \\
\hline$\sigma_{u}$ & $* * * 0.556$ & 0.210 & $* * * 0.488$ & \\
\hline Number of observations & 5552 & & 6276 & \\
\hline $\mathrm{BIC}$ & 2623 & & 1892 & \\
\hline $\mathrm{AIC}$ & 2411 & & 1676 & \\
\hline Log-Likelihood & -1173 & & -806 & \\
\hline
\end{tabular}

Note: ${ }^{1}$ Significant levels: $1 \%=* * * ; 5 \%=* * ; 10 \%=*$

All three specifications also show that $\sigma_{u}$ is significant, suggesting that unobserved individual effects follow a random distribution with zero means and non-zero variances. 
The effects of the remaining determinants on the probability of child obesity differ considerably within three specifications. For example, age of the child has no significant effects on obesity when BMI is selected, but the probability of being obese decreased with age when weight-for-age is selected or increase with age when self-reported obesity status is selected. The effects of high sugar drinks and time watching TV still have positive signs but no longer significant. The effects of neighbourhood facilities, in contrast, become significant and have expected positive signs: children in neighbourhood with poor infrastructure have significantly higher probability of being obese. The time trend and its interaction with income only significant at 10 per cent when child obesity is measured as those with the weight-for-age score at $95^{\text {th }}$ percentile or higher. Overall, the results remain mostly consistent when alternative measures of obesity are selected but model selection criteria (e.g., BIC, AIC and log-likelihood) suggest that the BMI-based specification in Table 2 is preferred.

\section{Conclusions}

The focus of this paper has been an examination of the dynamic nature of childhood obesity and the effect of household income on child obesity. We find a strong evidence of dynamic nature of child obesity: a child's current obesity is highly correlated with his/her previous obesity status. For example, being obese in the previous period has a $20.6 \%$ higher probability of being obese in the subsequent period. Our results also show that the incidence of child obesity in Australia is higher among poor households when a basic set of covariates are controlled for and the evolution of human health capital proposed by Grossman (1972) and Cunha \& Heckman (2007) is ignored. Our research also reveals a strong correlation between child and parental obesity. Shared genetics and environmental factors may contribute to this family- or household-based clustering of obesity. However, it is not possible to disentangle these two influences. Our research suggests that the consumption of drinks with a high sugar content and TV viewing are also positively associated with childhood obesity in this sample. Interestingly, after controlling for individual unobserved heterogeneity, we find that household income is no longer a significant determinant of child obesity in this sample.

Understanding the dynamics that affect childhood obesity is important for formulating appropriate public policy to mitigate this pervasive health problem. The most significant policy implications that stem from our 
research, are the promotion and increased awareness among parents of the relationship between their own consumption decisions and health outcomes (or risk factors) and the healthy development of their children. The creation of such awareness may play an important role in reducing the intergenerational transmission of obesity and its sequelae.

\section{References}

Altonji, J. G., Elder, T. E. and Taber, C. R. (2005). Selection on observed and unobserved variables: Assessing the effectiveness of catholic schools. Journal of Political Economy 113: 151-184.

Anderson, P. M., Butcher, K. F. and Levine, P. B. (2003). Maternal employment and overweight children. Journal of Health Economics 22: 477-504.

Au, N. (2012). The health care cost implications of overweight and obesity during childhood. Health Services Research 47: 655-676.

Australian Bureau of Statistics (2009). National Health Survey, Summary of Results, 2007-08. Cat. No. 4364.0. .

Australian Bureau of Statistics (2015). Consumer price index, australia.

Baltrus, P. T., Everson-Rose, S. A., Lynch, J. W., Raghunathan, T. E. and Kaplan, G. A. (2007). Socioeconomic position in childhood and adulthood and weight gain over 34 years: the alameda county study. Annals of Epidemiology 17: 608-614.

Baum II, C. and Ruhm, C. (2009). Age, socioeconomic status and obesity growth. Journal of Health Economics 28: 635-648.

Bhargava, A., Jolliffe, D. and Howard, L. L. (2008). Socio-economic, behavioural and environmental factors predicted body weights and household food insecurity scores in the early childhood longitudinal studykindergarten. British Journal of Nutrition 100: 438-444. 
Cawley, J. (2008). Contingent valuation analysis of willingness to pay to reduce childhood obesity. Economics and Human Biology 6: 281-292.

Chamberlain, G. (1980). Analysis of covariance with qualitative data. Review of Economic Studies 47: 225238.

Chia, Y. (2013). Dollars and pounds: the impact of family income on childhood weight. Applied Economics 45: 1931-1941.

Cunha, F. and Heckman, J. (2007). The technology of skill formation. American Economic Review 97: 3147.

Dietz, W. (1998). Health consequences of obesity in youth: childhood predictors of adult disease. Pediatrics 101: $518-525$.

El-Sayed, A. M., Scarborough, P. and Galea, S. (2012). Unevenly distributed: a systematic review of the health literature about socioeconomic inequalities in adult obesity in the united kingdom. BMC Public Health 12: 18.

Freedman, D., Mei, Z., Srinivasan, S., Berenson, G. and Dietz, W. (2007). Cardiovascular risk factors and excess adiposity among overweight children and adolescents: the bogalusa heart study. The Journal of pediatrics 150: 12-17.

Gregg, P., Washbrook, E., Propper, C. and Burgess, S. (2005). The effects of a mother's return to work decision on child development in the uk. Economic Journal 115: F48 - F80.

Grossman, M. (1972). On the concept of health capital and the demand for health. Journal of Political Economy 82: 223-255.

Han, J., Lawlor, D. and Kimm, S. (2010). Childhood obesity. The Lancet 375: 1737-1748.

Heckman, J. (2007). The economics, technology, and neuroscience of human capability formation. Proceedings of the National Academy of Sciences 104: 13250. 
Janicke, D. M., Harman, J. S., Kelleher, K. J. and Zhang, J. (2008). Psychiatric diagnosis in children and adolescents with obesity-related health conditions. Journal of Developmental and Behavioral Pediatrics 29: $276-284$.

Kennedy, B. P., Kawachi, I., Glass, R. and Prothrow-Stith, D. (1998). Income distribution, socioeconomic status, and self rated health in the united states: multilevel analysis. Bmj 317: 917-921.

Kuczmarski, R., Ogden, C., Guo, S. et al. (2002). 2000 CDC growth charts for the United States: Methods and development, 11(246). National Center for Health Statistics. Vital Health Stat.

Kuhle, S., Kirk, S. F. L., Ohinmaa, A. and Veugelers, P. J. (2011). Comparison of icd code-based diagnosis of obesity with measured obesity in children and the implications for health care cost estimates. $B M C$ Medical Research Methodology 11: 173.

Medicare Australia (2010). Obesity in Australia: financial impacts and cost benefits of intervention. Tech. rep., Medical Australia.

Murnane, R. J. and Willett, J. B. (2010). Methods matter: Improving causal inference in educational and social science research. Oxford University Press.

Murray, E. T., Mishra, G. D., Kuh, D., Guralnik, J., Black, S. and Hardy, R. (2011). Life course models of socioeconomic position and cardiovascular risk factors: 1946 birth cohort. Annals of Epidemiology 21: $589-597$.

Mushtaq, M. U., Gull, S., Abdullah, H. M., Shahid, U., Shad, M. A. and Akram, J. (2011). Prevalence and socioeconomic correlates of overweight and obesity among pakistani primary school children. $B M C$ Public Health 11: 724.

Nguyen, M., Beresford, S. and Drewnowski, A. (2007). Trends in overweight by socio-economic status in vietnam: 1992 to 2002. Public health nutrition 10: 115-121.

Norton, E. C. (2012). Log odds and ends. Tech. rep., National Bureau of Economic Research.

Price, J. and Swigert, J. (2012). Within-family variation in obesity. Economics and Human Biology 10: $333-339$. 
Soloff, C., Lawrence, D. and Johnstone, R. (2005). LSAC Technical Paper No. 1: Sample design. Tech. rep., Australian Institute of Family Studies, Melbourne, Australia.

Solt, F. (2009). Standardizing the world income inequality database*. Social Science Quarterly 90: 231-242.

Stamatakis, E., Wardle, J. and Cole, T. J. (2010). Childhood obesity and overweight prevalence trends in england: evidence for growing socioeconomic disparities. International journal of obesity 34: 41-47.

Sutherland, E. (2008). Obesity and asthma. Immunology and allergy clinics of North America 28: 589-602.

Thompson, D. and Wolf, A. M. (2001). The medical-care cost burden of obesity. Obesity Reviews 2: 189197.

Walsh, B. and Cullinan, J. (2015). Decomposing socioeconomic inequalities in childhood obesity: Evidence from ireland. Economics \& Human Biology 16: 60-72.

Wang, Y. and Lobstein, T. (2006). Worldwide trends in childhood overweight and obesity. International Journal of Pediatric Obesity 1: 11-25.

Webbink, D., Martin, N. and Visscher, P. (2010). Does education reduce the probability of being overweight? Journal of Health Economics 29: 29-38.

Wenig, C. M., Knopf, H. and Menn, P. (2011). Juvenile obesity and its association with utilisation and costs of pharmaceuticals-results from the kiggs study. BMC Health Services Research 11: 340.

Whitlock, E., Williams, S., Gold, R., Smith, P. and Shipman, S. (2005). Screening and interventions for childhood overweight: a summary of evidence for the us preventive services task force. Pediatrics 116: e125-e144.

Williams, J., Wake, M., Hesketh, K., Maher, E. and Waters, E. (2005). Health-related quality of life of overweight and obese children. JAMA: the Journal of the American Medical Association 293: 70-76.

Wooldridge, J. M. (2005). Simple solutions to the initial conditions problem in dynamic, nonlinear panel data models with unobserved heterogeneity. Journal of Applied Econometrics 20: 39-54. 
Zere, E., Kirigia, J. M., Duale, S. and Akazili, J. (2012). Inequities in maternal and child health outcomes and interventions in ghana. BMC Public Health 12: 252. 